\title{
Association Between Pericentric Inversion in Chromosome 9 and Congenital Heart Defects
}

\author{
Smitha Ramegowda ${ }^{1}$, Mysore R. Savitha ${ }^{2}$, Balasundaram Krishnamurthy ${ }^{2}$, Narayanappa Doddaiah \\ ${ }^{3}$, Subramanyam N. Prasanth ${ }^{3}$ and Nallur B. Ramachandra, ${ }^{1, *}$ \\ ${ }^{1}$ Human Genetics Laboratory, Department of Studies in Zoology, University of Mysore, \\ Manasagangothri, Mysore 570006, Karnataka, India \\ ${ }^{2}$ Department of Pediatrics, Cheluvamba Hospital, Mysore, Karnataka, India \\ ${ }^{3}$ Department of Pediatrics, JSS Hospital, Mysore, Karnataka, India
}

KEYWORDS Chromosomal anomalies; congenital heart disease; heart development; South India

ABSTRACT Congenital heart disease (CHD) is the leading cause of mortality in the first year of life. Prevalence of CHD worldwide is found to range from 1.0 to 50.89 per 1000 livebirths including India. The association of these defects with chromosomal anomalies varies between 4 to $12 \%$. In the present investigation, we report two different cases of pericentric inversion of chromosome 9 [inv(9)(p11-q13)], associated with Total Anomalous Pulmonary Venous Connection (TAPVC) and Tetralogy of Fallot (TOF). In one of the cases (TOF), the mother had similar inversion without CHD. We predict here that, the genes responsible for the normal heart development could be present on chromosome 9 around p11-q13 region, which might have been defective during the process of inversion and thereby resulted in CHD. To our knowledge, this is the maiden report of association of inversion with CHD from South India.

\section{INTRODUCTION}

Congenital heart disease (CHD) is the malformations of the heart or the large blood vessels associated with the heart, affecting various parts or function. It is one of the leading causes of death in the first year of life (Srivastava 2001). Prevalence of CHD worldwide is found to range from 1.0 to 50.89 per 1000 livebirths including India (Smitha et al. 2006). These are grouped as multifactorial defects, however about 4 to $12 \%$ of the CHDs are found to be associated with various chromosomal anomalies (Smitha and Ramachandra 2005).

Cytogenetic aberrations on chromosome 9 (aneuploidy, deletions, translocations, inversions) have been reported to be one of the most frequent abnormalities. The range of phenotypic consequences found to be associated with these abnormalities are mild growth retardation, malformations of the skull and facial (craniofacial) region, abnormalities of the hands and fingers, skeletal malformations, and/or cardiac defects

Addres for Correspondence: Dr. N. B. Ramachandra ${ }^{1}$ Human Genetics Laboratory, Department of Studies in Zoology, University of Mysore, Manasagangothri, Mysore 570006 Karnataka, India Telephone: R-0821-2516056; Mobile: 09880033687 E-mail: nallurbr@gmail.com
(Boby et al. 1994; Mokhtar 1997; McAuliffe et al. 2005).

Among these anomalies pericentric inversion of chromosome 9 is one of the most common balanced structural chromosomal aberrations found in 1 to $3 \%$ of the general population (Nielson and Silesen 1975; Ko et al. 1992; Teo et al. 1995; Humphray et al. 2004). However, there are several conflicting reports on the association of this inversions with subfertility, sterility, recurrent miscarriage, schizophrenia, congenital myotonic dystrophy, cerebral cyst, dysmorphic signs, mental retardation, psychiatric disorders and other abnormal clinical conditions (Krishna et al. 1992; Scarinci et al. 1992; Teo et al. 1995; Gardner and Sultherland 1996, Kunugi et al. 1999; Davalos et al. 2000; Parmar and Sira 2003; Srebniak et al. 2004). This particular pericentric inversion has also been implicated as a possible predisposing factor for nondisjunction and interchromosomal effect (Krishna et al. 1992). Individuals carrying such inversions have an increased risk of unbalanced progeny ranging from 1 to 10\% (Gardner and Sultherland 1996).

In the present investigation, we report two cases of pericentric inversion of chromosome 9 in heterozygous condition with CHDs of which, one is a familial case. 


\section{MATERIALS AND METHODS}

\section{Case Report}

Case 1: The male proband was the first-born child of nonconsanguineous parents, spontaneously delivered after an uneventful pregnancy with a birth weight of 2.5 kilograms. Clinical investigations revealed the presence of CHDs with no other clinical abnormalities. Echocardiographic examination of the proband confirmed the presence of total anomalous pulmonary venous connection as the defect (TAPVC). For further investigations, the proband was referred for cytogenetic investigation.

Case 2: The male proband was the second twin child born to nonconsanguineous parents (Fig. 1), delivered by caesarean operation after an uneventful pregnancy with a birth weight of 2 kilograms. Clinical investigations of the proband revealed the presence of CHD. Echocardiographic studies confirmed the CHD as tetralogy of fallot (TOF). The proband was further referred for echocardiographic examination and cytogenetic analysis.

\section{Cytogenetic Studies}

With the consent of the family members, chromosomal analysis for both the probands and parents of case two was carried out on peripheral blood lymphocyte culture using standard protocol of Seabright (1971), with little modifications. Giemsa banded metaphases were screened using Leica DMRA2 research microscope. A total of 50 well-banded metaphase plates were analyzed and karyotyped according to the International System for Human Cytogenetic Nomenclature (ISCN 1995).

\section{RESULTS}

Case 1: Pedigree analysis revealed that there was no history of birth defects or genetic defects

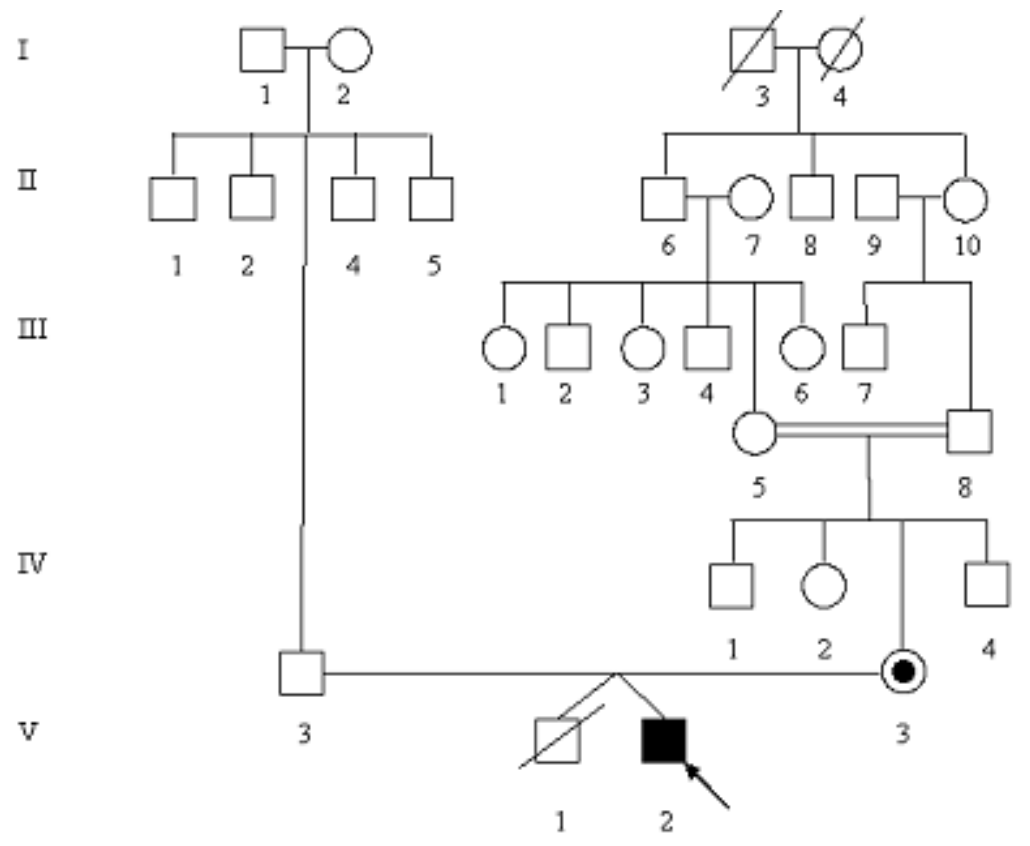

Fig. 1. Pedigree of the family of case two with $\operatorname{inv}(9)(p 11-q 13)$ in the proband and the mother The symbols which are square indicate males and circle indicate females; the arrow directed to the shaded symbol represents the proband, the shaded dot in the circle denotes the inversion carrier mother. The Roman number in the left side of the figure indicates the number of generations. The Arabic number below the symbol denotes the number of individuals in that generation. The double line between the maternal grandparents of the proband indicates the consanguineous marriage (first cousin marriage). The crossed line on the symbols indicates the individual as deceased. 
in the family. Conventional cytogenetics (Gbanding) revealed 46,XY,inv(9)(p11-q13) in all the 50 metaphase plates screened (Fig. 2). Chromosomal investigations could not be carried out on the parents as they declined to take part in the investigation.

Case 2: Pedigree analysis revealed that there was no history of birth defects or genetic defects in the family. However, clinically the first twin who had not shown any symptoms of CHD, died after few days of birth due to continues refusal of feed. It was also seen that maternal grand-parents were related (first cousin consan-guineous marriage). Conventional cytogenetics on the probands chromosomes revealed 46,XY,inv(9)(p11-q13) in all the 50 metaphase plates screened (Fig. 3). Cytogenetic investigation in the mother also revealed 46,XX,inv(9)(p11-q13) (Fig. 4), whereas the father revealed normal karyotype. Echocardiographic examinations in the parents did not reveal any CHD or any other abnormalities.

\section{DISCUSSION}

Congenital heart anomalies constitute a major malformation leading to significant morbidity and mortality eventually affecting the clinical outcome of the affected individuals. There are several reports of CHDs associated with chromosomal variations like trisomies, deletions, duplications and translocations (see, Smitha and Ramachandra 2005). However, there are no reports of association of pericentric inversion of chromosome 9 [inv(9)(p11-q13)] with CHDs. This pericentric inversion is believed to be a frequent occurrence in the general population and inherited in a Mendelian fashion or might appear for the first time in a child without any apparent phenotypic consequences (Nielson and Silesen 1975; Ko et al. 1992; Luke et al. 1992; Teo et al. 1995; Humphray et al. 2004). Interestingly, in the present findings, we found the association of same inversion with two different CHDs (1.70\%) of the total 117 CHD cases studied. In the first case study, the proband was diagnosed clinically with TAPVC and cytogenetically with the inv(9)(p11-q13). In the second case study, proband was diagnosed clinically with TOF and cytogenetically with the inv(9)(p11-q13). When parents were screened clinically by echocardiographic examination none of them had CHD, but cytogenetic investigation revealed the inv(9) (p11-q13) only in mother.
One of the possible explanations for the presence of CHD in the second case with this inversion could be that the mother might have this pericentric inversion due to de novo event, which the proband inherited. However, during the process of inheritance of the inversion some gene/s, which is required for the normal development of the heart, might have undergone mutation resulting in CHD in the proband. To support this hypothesis, there are several studies, which state that the individuals carrying, such inversions have an increased risk of unbalanced progenies (Gardner and Sultherland 1996) and this inversion is a possible predisposing factor for nondisjunction and interchromosomal effect (Krishna et al. 1992).

We predict here that this pericentric inversion of chromosome 9 and associated mutations have resulted in the occurrence of CHDs in both the probands. In support of this, there are reports about abnormalities of chromosome 9 associated with several cardiac anomalies which includes truncus arteriosus, truncal valve stenosis, single carotid trunk, subclavian arteries arising from the distal part of the aortic arch, atrial and ventricular septal defects, atrioventricular septal defect, pulmonary artesia, right ventricular hypertrophy and hypoplastic left pulmonary artery (Roberts et al. 1993; Nekarda et al. 1997; Sepulveda et al. 2003). In particularly, the chromosome $9 p$ is found to be associated with series of CHDs, like ventricular septal defect with pulmonary valve stenosis and a marked hypoplasia of the pulmonary trunk (Schimmenti et al. 1995; Leichtman et al. 1996; Nakagawa et al. 1999).

Although, development of the heart involves cascade of events involving several genes on different chromosomes, which includes Nkx2-5, Gata4, Tbx5, etc. (Srivastava 2001), studies on molecular level to unravel the gene/s on chromosome 9 which might contribute to the development of the heart, have limited success. Apart from the studies by Scott et al. (1998) who mapped the ZNF216 gene within a 1.5-Mb DFNB7/ 11 interval in 9q13-q21 region, which was found to express highly in brain, muscle, eye, and heart in mouse studies and the present study, no other studies have reported the contribution of chromosome 9 in the heart development. However, these reports indicate that there are genes in this particular region whose contribution to the normal development of the heart is vital and any structural abnormality in the chromosome 9 will lead to CHD. 


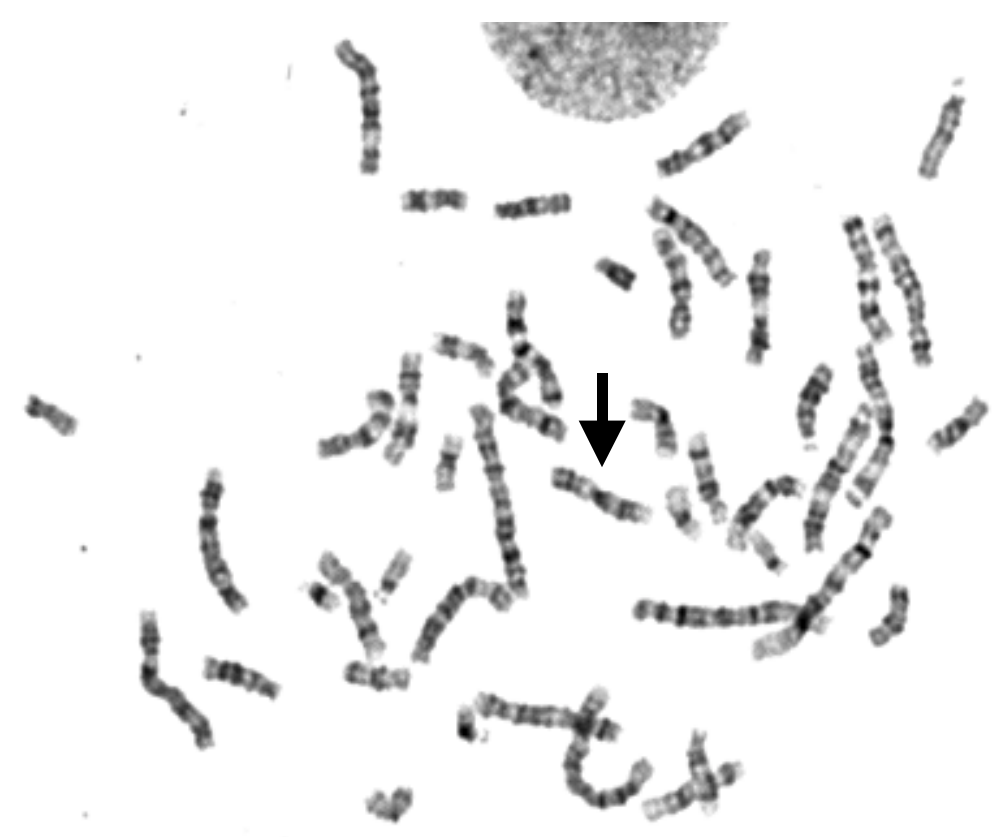

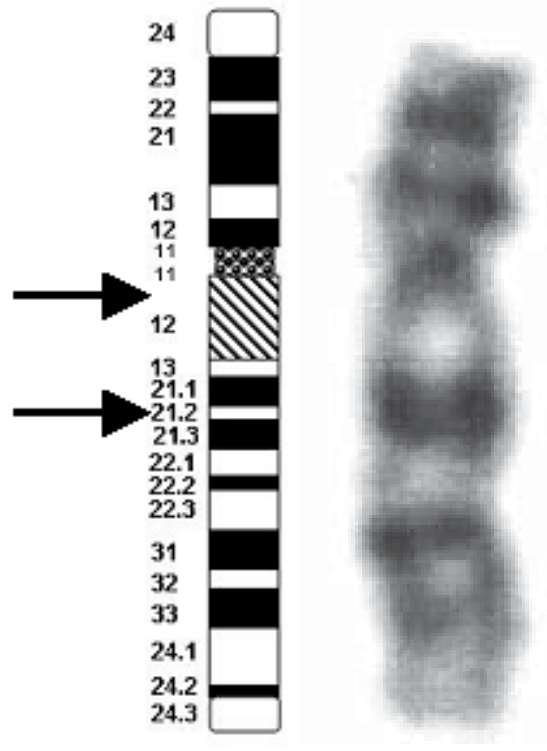

b Normal chromosome 9

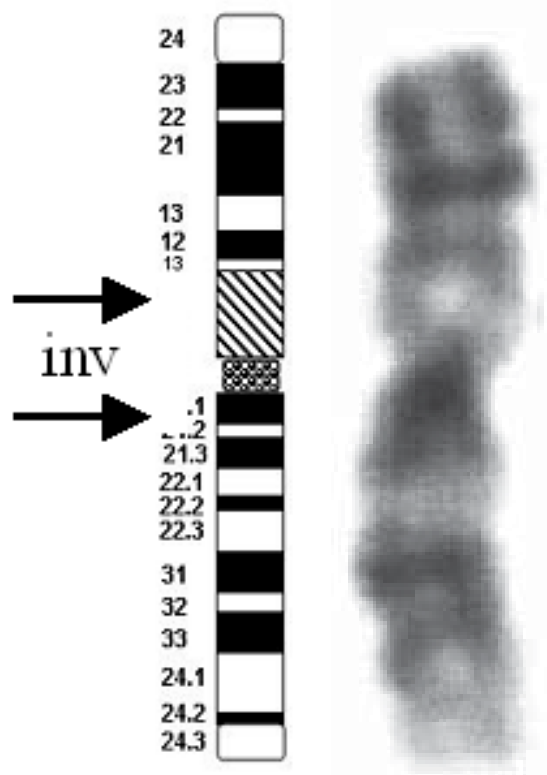

Inverted chromosome 9

Fig. 2. G banded Chromosomes of the case one proband with inv(9)(p11-q13)

(a) G banded metaphase plate showing inv(9)(p11-q13) (arrow), (b) enlarged view of chromosome 9 without and with inversion along with the respective ideogram. 
a
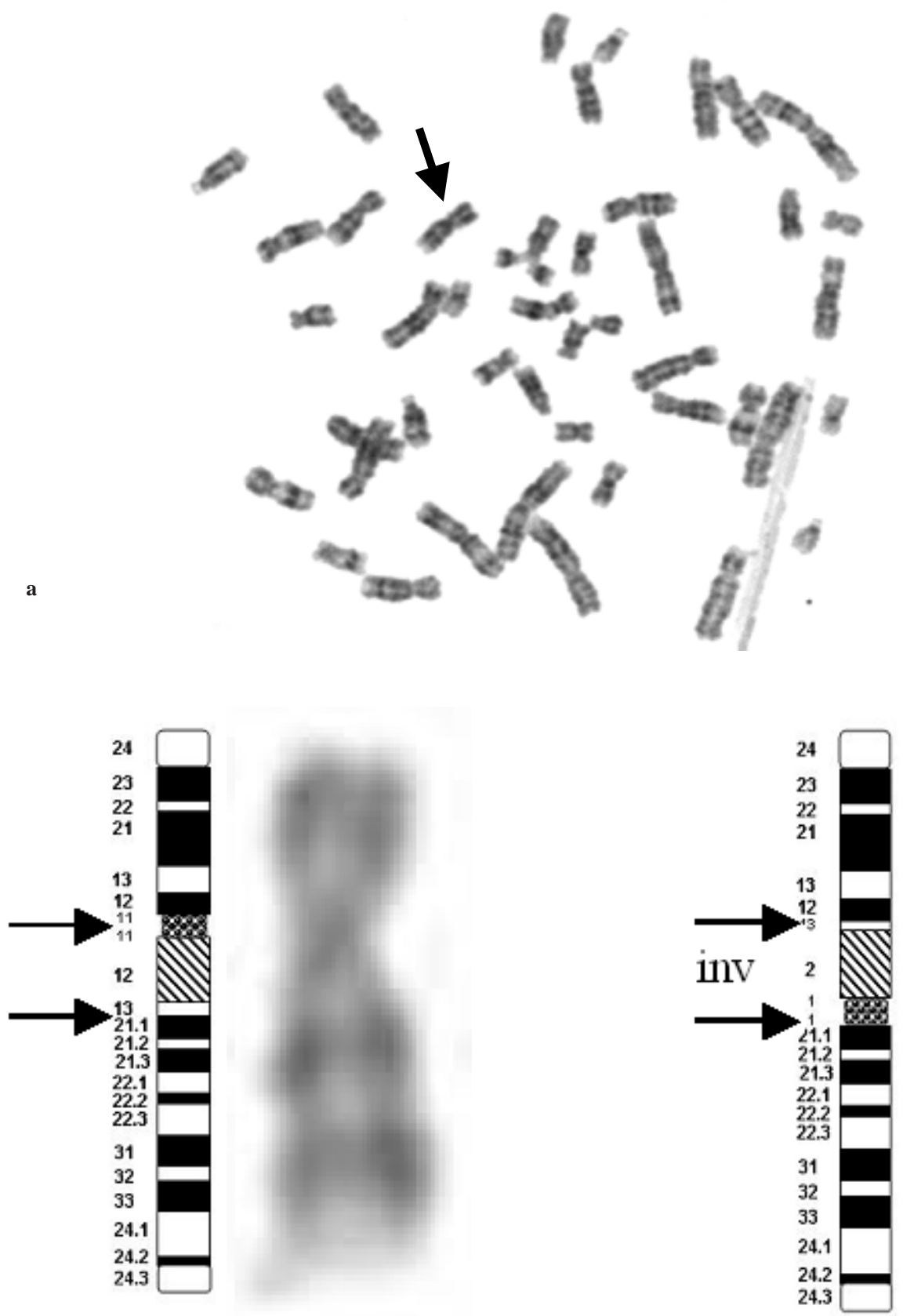

b

Normal chromosome 9

Inverted chromosome 9

Fig. 3. Chromosomes of the case 2 proband with inv(9)(p11-q13)

(a) G banded metaphase plate showing inv(9)(p11-q13) (arrow), (b) enlarged view of chromosome 9 without and with inversion along with the respective ideogram. 
a
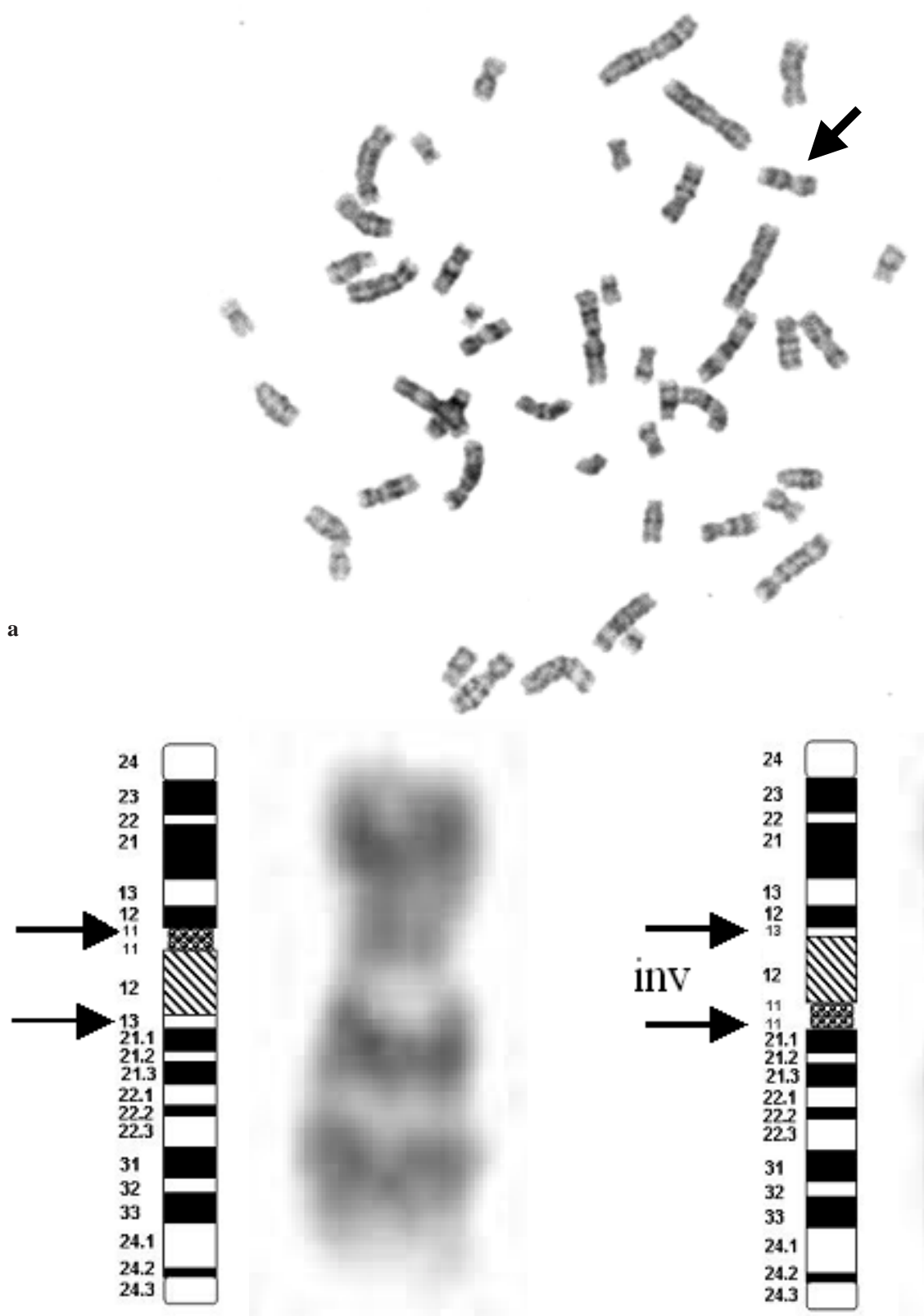

b

Normal chromosome 9

Inverted chromosome 9

Fig. 4. Chromosomes of the mother of case 2 with inv(9)(p11-q13)

(a) G banded metaphase plate showing inv(9)(p11-q13) (arrow), (b) enlarged view of chromosome 9 without and with inversion along with the respective ideogram. 
There are several reports of the association of this inversion with several abnormal clinical conditions like schizophrenia, congenital myotonic dystrophy, cerebral cyst, dysmorphic signs, mental retardation, psychiatric disorders and other abnormal clinical conditions (Krishna et al. 1992; Scarinci et al. 1992; Teo et al. 1995; Gardner and Sultherland 1996, Kunugi et al. 1999; Davalos et al. 2000; Parmar and Sira 2003). and the adult carriers are subfertile and suffer recurrent miscarriages (Srebniak et al. 2004). In contrast to this, in our investigations apart from CHDs in both the probands there were no other clinical abnormalities. In the second case study, the mother did not suffer any miscarriage or any other abnormalities although she had this particular inversion.

Reports are also available concerning carriers of pericentric inversion of chromosome 9 showing different clinical anomalies (Scarinci et al. 1992). However, there are no reports of such inversion associated with CHD. To our knowledge, this is the maiden report of association of inversion with CHDs from South India. We predict here, that the genes responsible for the normal heart development could be present on chromosome 9 around p11-q13 region, which might have been defective during the process of inversion and thereby resulted in CHD.

\section{ACKNOWLEDGMENTS}

We thank the family members who have taken part in the present study. Written consent was obtained from the parents for publication of study. We thank DST, New Delhi for providing FIST grants to Department of Zoology. We thank Department of Pediatric, Cheluvamba Hospital, Mysore; Department of Pediatric, J.S.S Hospital, Mysore; Doctors and PG students of the both the hospitals for the support and help, Prof. H. A. Ranganath for his encouragement, Mr. Harshavardhan M. Gawde, Dr. Mikhil N. Bamne, Dr. Nagaraj and Ms Pushpa Saviour who have rendered their immense help for this study.

\section{REFERENCES}

Boby J, Karande SC, Lahiri KR, Jain MK, Kanade S 1994. 9p-Syndrome. J Postgrad Med, 40(1): 40 - 41.

Davalos IP, Rivas F, Ramos AL, Galaviz C, Sandoval L, Rivera H 2000. inv(9)(p24q13) in three sterile brothers. Annales de Genetique, 43: 51-54.

Gardner RJM, Sultherland GR 1996. Chromosome abnormalities and genetic counseling. Oxf Monogr Med Genet, 29: 139-152.

Humphray SJ, Oliver K, Hunt AR, Plumb RW, Loveland JE, Howe KL 2004. DNA sequence and analysis of human chromosome 9. Nature, 429(6990): 369-374.

International System for Human Cytogenetic Nomenclature. Editor: Felix Mitelman, Karger publication (ISCN 1995).

Ko TM, Hsieh FJ, Chang LS, Pan MF, Lee TY 1992. Pericentric inversions of chromosome 9 in Taiwanese fetuses. J Formos Med Assoc, 91(4): 473-474.

Krishna DS, Al-Awadi SA, Farag TI 1992. Pericentric inversion and recombinant aneusomy and other associated chromosomal aberrations: random or non-random. Am J Hum Genet, 51(4): A291(1146).

Kunugi H, Lee KB, Nanko S 1999. Cytogenetic findings in 250 schizophrenics: evidence confirming an excess of the chromosome aneuploidies and pericentric inversion of chromosome 9. Schizophr Res, 40: 43-47.

Leichtman LG, Zackowski JL, Storto PD, Newlin A 1996. Non-mosaic tetrasomy $9 p$ in a liveborn infant with multiple congenital anomalies: case report and comparison with trisomy 9p. Am J Med Genet, 63(3): 434-437.

Luke S, Verma RS, Conte RA, Mathews T 1992. Molecular characterization of the secondary constriction region (qh) of human chromosome 9 with pericentric inversion. J Cell Sci, 103: 919-923.

McAuliffe F, Winsor EJ, Chitayat D 2005. Tetrasomy $9 \mathrm{p}$ mosaicism associated with a normal phenotype. Fetal Diagn Ther, 20(3): 219-222.

Mokhtar MM 1997. Chromosomal aberrations in children with suspected genetic disorders. Eastern Mediterranean Health Journal, 3(1): 114-122.

Nakagawa M, Kato H, Aotani H, Kondo M 1999. Ebstein's anomaly associated with trisomy $9 p$. Clin Genet, 55(5): 383-385.

Nekarda T, Kececioglu D, Kehl HG, Gehrmann J, Miny P, Vogt J 1997. A rare combination of partial trisomy 9 with pulmonary atresia. Klin Padiatr, 209(3): 127-129.

Nielsen J and Sillesen I 1975. Incidence of chromosome aberrations among 11,148 newborn children. Hum Genet, 30: 1-12.

Parmar RC, Sira P 2003. Prenatal diagnosis of partial trisomy 21 associated with maternal balanced translocation 46xx der 21 t(21q;22q) with pericentric inversion of chromosome 9. J Postgrad Med, 49: 154-156.

Roberts DJ, Sandstrom MM, Van Praagh S 1993. Characteristics of structural heart defects in trisomy 9 and their relationship to those in trisomy 13, 18, and 21. Am Heart J, 125(6): 1681-1690.

Scarinci R, Anichini C, Vivarelli R, Berardi R, Pucci L, Rosaia L, Tomaccini D 1992. Correlation of the clinical phenotype with a pericentric inversion of chromosome 9. Boll Soc Ital Biol Sper, 68(3): 175-181.

Schimmenti LA, Higgins RR, Mendelsohn NJ, Casey TM, Steinberger J, Mammel MC, Wiesner GL 1995. Monosomy 9p24-> pter and trisomy 5q31 $>$ qter: case report and review of two cases. Am J Med Genet, 57(1): 52-56.

Scott DA, Greinwald JH, Jr, Marietta JR, Drury S, 
Swiderski RE, Vinas A, DeAngelis MM, Carmi R, Ramesh A, Kraft ML, Elbedour K, Skworak AB, Friedman RA, Srisailapathy CRS, Verhoeven K, Van Camp G, Lovett M, Deininger PL, Batzer MA, Morton CC, Keats BJ, Smith RJH and Sheffield VC 1998. Identification and mutation analysis of a cochlearexpressed, zinc finger protein gene at the DFNB7/11 and $\mathrm{dn}$ hearing-loss-loci on human chromosome $9 \mathrm{q}$ and mouse chromosome 19. Gene, 215: 461-469.

Seabright M 1971. A rapid banding technique for human chromosomes. Lancet, 2: 971-972.

Sepulveda W, Wimalasundera RC, Taylor MJ, Blunt S, Be C, De La Fuente S 2003. Prenatal ultrasound findings in complete trisomy 9. Ultrasound Obstet Gynecol, 22(5): 479-483.

Smitha R, Karat SC, Narayanappa D, Krishnamurthy B,
Prasanth SN, Ramachandra NB 2006. Prevalence of congenital heart diseases in Mysore. Ind J Hum Genet 12(1): 12-17.

Smitha R and Ramachandra NB 2005. An understanding the genetic basis of congenital heart disease. Ind $J$ of Hum Genet, 11(1): 14-23.

Srebniak M, Wawrzkiewicz A, Wiczkowski A, Kazmierczak W, Olejek A 2004. Subfertile couple with $\operatorname{inv}(2), \operatorname{inv}(9)$ and 16qh+. J Appl Genet, 45(4): 477-479.

Srivastava D 2001. Genetic assembly of Heart: Implication of congenital heart disease. Аппи Rev Physiol, 63: 451-469.

Teo SH, Tan M, Knight L, Ng I 1995. Pericentric inversion 9-incidence and clinical significance. Ann Acad Med Singapore, 24: 302-304. 